\title{
STRATEGI PENGEMBANGAN LAPAN MENJADI LEMBAGA PENILAIAN KESESUAIAN DAN KESIAPAN INFRASTRUKTUR LABORATORIUM UNTUK PENERAPAN STANDAR BIDANG PENERBANGAN DAN ANTARIKSA

\author{
LAPAN Development Strategy Become Conformity Assessment Bodies and \\ Laboratory Infrastructure Readiness For Implementation Of Standards Of Aeronautic \\ And Space
}

\author{
Hogan Eighfansyah Susilo \\ Lembaga Penerbangan dan Antariksa Nasional \\ Jalan Pemuda Pemuda Persil No.1, Rawamangun, Jakarta Timur \\ e-mail: hogan.eighfansyah@lapan.go.id
}

\begin{abstract}
Abstrak
Sebagaimana diamanatkan UU No. 21 tahun 2013 Tentang Keantariksaan Bahwa setiap penyelengaraan keantariksasn harus memenuhi norma, pedoman dan standar. LAPAN sebagai lembaga pemerintah yang bertugas di bidang penerbangan dan antariksa memiliki fungsi pelaksanaan pengelolaan standardisasi di bidang penerbangan dan antariksa. LAPAN telah mengeluarkan pedoman yang tertuang dalam Peraturan Kepala Lembaga Nomor 10 Tahun 2017 tentang Pelaksanaan Standardisasi Penerbangan dan Antariksa yang salah satunya mengatur tentang penerapan standar dan penilaian kesesuaian dimana penilaian kesesuaian dilakukan melalui kegiatan pengujian, inspeksi, dan sertifikasi. Kegiatan ini salah satunya dihasilkannya 2 SNI produk. Namun pelaksanaan standardisasi penerbangan dan antariksa masih terhambat dikarenakan belum ada ketersediaan Lembaga Penilaian Kesesuaian (LPK) seperti laboratorium pengujian, lembaga inspeksi dan lembaga sertifikasi produk yang kompeten sebagai infrastruktur penerapan standar. Kondisi LAPAN yang didukung oleh SDM dan sarana- prasarana penunjang litbang keantariksaan seperti laboratorium seharusnya dapat menjadi LPK dibidang penerbangan dan antariksa. Maka perlu adanya penelitian mengenai strategi pengembangan LAPAN menjadi LPK untuk mendukung penguatan infrastruktur penerapan standar bidang penerbangan dan antariksa menjadi penting untuk dilakukan. Dari hasi analisis SWOT dan analisis kesenjangan ISO/IEC 17025 tentang laboratorium pengujian bahwa posisi Organisasi LAPAN dalam berada di kuadran II (positif, negatif). Posisi ini menandakan sebuah organisasi yang kuat namun menghadapi tantangan yang besar. sehingga diperkirakan operasional organisasi akan mengalami kesulitan untuk menjalankan fungsi infrastruktur penerapan standar bila hanya bertumpu pada struktur organisasi yang ada. Sedangkan untuk tingkat kesiapan Laboratorium pengujian masih cukup rendah. Unit laboratorium yang cukup siapa adalah unit laboratorium di Pusat Teknologi Penerbangan.
\end{abstract}

Kata kunci: LAPAN, Lembaga Penilaian Kesesuaian, ISO/IEC 17025, SWOT, Analisis Kesenjangan

\begin{abstract}
As mandated by UU No. 21 of 2013 concerning Space that every implementation of space must meet norms, guidelines, and standards. LAPAN as a government agency in charge of aeronautics and space has the function of implementing standardization management in the field of aeronautics and space. LAPAN has issued the guidelines contained in Perka LAPAN No. 10 of 2017 concerning Implementation of Aeronautics and Space Standardization, one of which regulates the application of standards and conformity assessment where conformity assessment is carried out through testing, inspection, and certification activities. However, the implementation of aeronautics and space standardization is still hampered due to the unavailability of Conformity Assessment bodies (LPK) such as testing laboratories, inspection bodies and competent product certification bodies as infrastructure for implementing standards. LAPAN conditions that are supported by human resources and supporting infrastructure for R\&D facilities such as laboratories should be able to become LPK in the field of aeronautics and space.Hence, the need for research on the development strategy LAPAN become LPK to support the strengthening of infrastructure for implementation of aviation and space standards is important to do. From the results of the SWOT analysis and ISO / IEC 17025 gap analysis of testing laboratories that the LAPAN Organization's position is in quadrant II (positive, negative). This position indicates a strong organization but face great challenges. It is estimated that the operational organization will find it difficult to run a standard application infrastructure functions if only rely on the existing organizational structure. Whereas the level of readiness for testing laboratories is still quite low. The unit is quite prepared laboratory laboratory unit at the Center for Aviation Technology (Pustekbang).
\end{abstract}

Keyword: LAPAN, Conformity Assessment Bodies, ISO/IEC 17025, SWOT, Gap Analysis. 


\section{PENDAHULUAN}

Sebagaimana diamanatkan UU No 21 Tahun 2013 Tentang Keantariksaan, bahwa Pemerintah wajib melakukan pembinaan terhadap Penyelenggaraan Keantariksaan meliputi aspek pengaturan yang terdiri atas penentuan norma, pedoman dan standar serta aspek pengendalian yang meliputi pemberian, pelatihan, perizinan sertifikasi dan pemberian bantuan teknis dibidang pembangunan dan pengoperasian.

LAPAN melaksanakan tugas

pemerintahan di bidang penelitian dan pengembangan kedirgantaraan serta penyelenggaraan keantariksaan, seperti tercantum dalam Peraturan Presiden No 49 Tentang Lembaga Penerbangan dan Antariksa Nasional (LAPAN). Dalam melaksanakan tugas sebagaimana dimaksud, LAPAN menyelenggarakan fungsi pelaksanaan pengelolaan standardisasi bidang penerbangan dan antariksa. LAPAN bertindak sebagai instansi teknis yang berwenang melaksanakan pembinaan dan pengawasan penerapan standar terhadap pelaku usaha dan penyelenggara keantariksaan. Sebagai tindak lanjut pelaksanaan fungsi pengelolaan standardisasi penerbangan dan antariksa, LAPAN telah mengeluarkan pedoman yang tertuang dalam Peraturan Kepala Lembaga Nomor 10 Tahun 2017 tentang Pelaksanaan Standardisasi Penerbangan dan Antariksa yang salah satunya mengatur tentang penerapan standar dan penilaian kesesuaian dimana penilaian kesesuaian dilakukan melalui kegiatan pengujian, inspeksi, dan sertifikasi.

Pada tahun 2018 Badan Standardisasi Nasional (BSN) telah menetapkan 2 (dua) Komite Teknis (Komtek) Perumusan SNI Bidang Penerbangan dan Antariksa dimana LAPAN sebagai Sekretariatnya, dengan adanya Komtek Perumusan SNI tersebut, akan mendorong program pengembangan standar di bidang penerbangan dan antariksa berdimensi nasional yang akan berdampak kepada meluasnya kebutuhan penerapan standar oleh stakeholder penyelenggaraan keantariksaan.Pada awal tahun 2019, telah dilakukan perumusan Standar Nasional Indonsia (SNI) dibidang teknologi penerbangan dan antariksa yang menghasilkan RSNI satelit kubus (cubesat) dan RSNI radar hujan. Standar satelit kubus ini merupakan standar yang diadopsi dari standar ISO 17770:2017 dan dimodifikasi sesuai dengan kebutuhan dan teknologi yang sedang berkembang. Sedangkan radar hujan merupakan radar pemantau curah hujan spasial suatu wilayah. Standar ini merupakan standar hasil pengembangan sendiri. Rancangan standar ini selanjutnya akan ditetapkan pada tahun 2019.

Standarini, pada dasarnya diterapkan secara sukarela. Namun demikian, dalam rangka kepentingan umum, keamanan, keselamatan, pelestarian lingkungan hidup, serta perkembangan perekonomian nasional, SNI dapat diberlakukan secara wajib oleh pemerintah. Pemberlakuan penerapan SNI wajib harus mempertimbangkan berbagai aspek agar tidak tidak terjadi persaingan yang tidak sehat, menghambat inovasi teknologi dan menghambat perkembangan industri, UKM dan transaksi perdagangan. Namun, dalam pelaksanaannya SNI yang diberlakukan secara wajib mengalami permasalahan terkait penerapannya, yang disebabkan oleh ketersediaan Lembaga Penilaian Kesesuaian (LPK) seperti laboratorium pengujian, lembaga inspeksi dan lembaga sertifikasi produk yang kompeten sebagai infrastruktur penerapan standar.LPK berfungsi untuk menyatakan kesesuaian barang dan jasa terhadap pemenuhan persyaratan SNI yang ditetapkan. Penerapan SNI secara wajib maupun sukarela harus didukung dengan kesiapan infrastruktur teknis penerapan standarnya berupa lembaga penilaian kesesuaian yang kompeten.

Saat ini penyelenggaraan keantariksaan yang memenuhi standar di Indonesia masih menjadi kendala, hal ini dikarenakan belum tersedianya LPK di bidang penerbangan dan antariksa yang melakukan penilaian kesesuaian terhadap pemenuhan persyaratan SNI yang ditetapkan. Dengan kondisi tersebut, LAPAN sebagai instansi teknis yang bertugas pembinaan dan pengawasan penyelenggaraan keantariksaan yang didukung oleh SDM dan sarana- prasarana penunjang litbang keantariksaan seperti laboratorium seharusnya dapat menjadi LPK dibidang penerbangan dan antariksa. Namun demikian, laboratorium dan fasilitas keantariksaan tersebut belum menjadi LPK yang terakreditasi. Oleh karenanya,perlu diketahui kondisi laboratorium dan fasilitas keantariksaan yang dimiliki LAPAN saat ini sehingga dapat ditentukan pula hal-hal yang perlu dilakukan untuk mengembangkannya sehingga dapat terakreditasi menjadi LPK yang berperan penting dalam proses sertifikasi. Berdasarkan hal tersebut, pertanyaan besar yang akan dijawab dalam penelitian ini adalah:

1) Bagaimana kondisi kesiapan laboratorium dan fasilitas keantariksaan yang dimiliki 
LAPAN untuk menjadi LPK yang terakreditasi berkaitan dengan standar yang akan ditetapkan?

2) Bagaimana potensi Organisasi LAPAN saat ini dalam pelaksanaan standardisasi, dan strategi kompetitif apa yang dilakukan untuk memperkuat infrastruktur penerapan standar bidang penerbangan dan antariksa ?

\section{TINJAUAN PUSTAKA}

\section{a. Infrastruktur Penerapan Standar}

Standar adalah dokumen yang memuat ketentuan spesifikasi teknis atau sesuatu yang dibakukan termasuk tata cara dan metode yang disusun berdasarkan konsensus semua pihak yang terkait dengan memperhatikan syarat-syarat keselamatan, keamanan, kesehatan, lingkungan hidup, perkembangan ilmu pengetahuan dan teknologi, pengalaman, serta perkembangan masa kini dan masa yang akan datang untuk memperoleh manfaat yang sebesar-besarnya (UU No 20 tahun 2014).

Pada prinsipnya penerapan standar dilakukan secara sukarela, khususnya dipergunakan oleh produsen atau pelaku usaha sebagai acuan dalam pengendalian mutu internal atau untuk kepentingan promosi bahwa produk yang diproduksi memiliki kualitas baik dan terjamin. Penerapan standar dapat bersifat wajib jika menyangkut keselamatan, kesehatan, keamanan, atau kelestarian fungsi lingkungan hidup. Pemberlakuan standar secara wajib ditetapkan oleh Menteri atau Kepala Lembaga terkait dengan mempertimbangkan berbagai faktor, yaitu mampu terap standar yang ditetapkan, kesiapan industri/produsen dalam negeri, kesiapan lembaga penilaian kesesuaian, dan kesiapan pengawasan oleh pemerintah, serta tidak bertentangan dengan kesepakatan internasional (Herjanto dan Rahmi, 2010).

Penerapan standar dimaksudkan untuk meningkatkan perlindungan kepada konsumen, pelaku usaha, dan masyarakat terhadap aspek keselamatan, keamanan, kesehatan maupun pelestarian fungsi lingkungan hidup, serta untuk membantu kelancaran perdagangan serta mewujudkan persaingan usaha yang sehat. Dengan adanya standar nasional maka akan ada acuan tunggal dalam mengukur mutu produk dan/atau jasa di dalam perdagangan.
Sebuah standar tidak akan dapat diterapkan bila tidak terdapat infrastruktur teknis yang diperlukan untuk membuktikan kesesuaian dengan persyaratan dalam standar tersebut(Shepherd, C. C,2014). Demikan halnya dengan pernyataan kesesuaian terhadap sebuah standar tidak akan dapat dipercaya oleh pihak lain bila pernyataan kesesuaian tersebut tidak diberikan oleh lembaga penilaian yang kompeten. Dengan demikian penerapan SNI perlu didukung oleh infrastruktur penerapan standar yang mencakup kelembagaan penilaian kesesuaian dan skema penilaian kesesuaian untuk menyatakan kesesuaian suatu proses, jasa atau suatu produk terhadap persyaratan SNI tertentu.

Penerapan standar perlu dibuktikan melalui kegiatan penilaian kesesuian oleh lembaga penilaian kesesuaian yang terakreditasi badan yang berwenang di bidang akreditasi(Mansuette, B., \& Cebekhulu, B., 2017)..Di Indonesia sesuai ketentuan dalam UU nomor 20 tahun 2014 tentang Standardisasi dan Penilaian Kesesuaian, bahwa Komite Akreditasi Nasional (KAN) adalah Lembaga nonstruktural yang berwenang dan bertanggung jawab di bidang Akreditasi Lembaga penilaian Kesesuaian.

Akreditasi adalah rangkaian kegiatan penilaian kesesuaian oleh KAN, yang menyatakan bahwa suatu lembaga penilaian kesesuaian memiliki kompetensi serta berhak

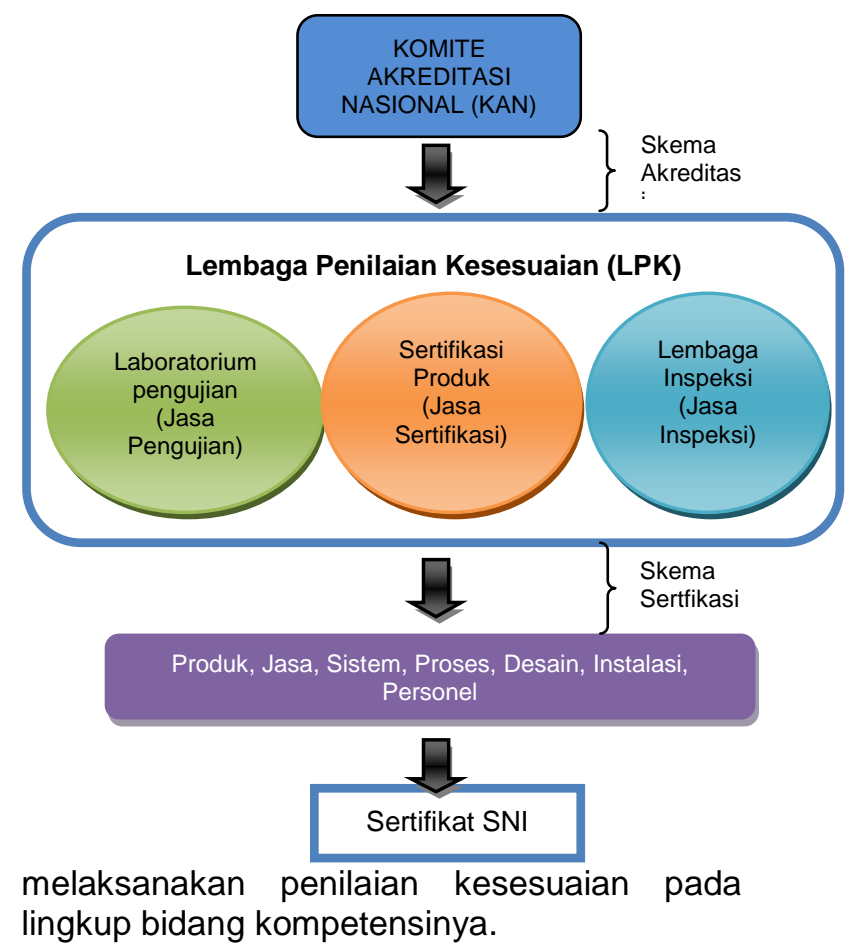

lingkup bidang kompetensinya.

Gambar 1. Infrastruktur Penerapan Standar 


\section{b. Sistem Penilaian Kesesuaian}

Setiadi (2011) menjelaskan bahwa penerapan SNI meliputi empat pilar penilaian kesesuaian mencakup akreditasi, pengujian, inspeksi. dan sertifikasi. Pengembangan SNI akan berhasil jika standar tersebut diterapkan oleh pelaku usaha. Penilaian kesesuaian menjadi sangat penting guna mendukung terwujudnya jaminan mutu barang, jasa, proses, sistem atau personil sehingga memberi kepercayaan pelanggan dan pihak terkait bahwa suatu organisasi, individu, barang dan/atau jasa yang diberikan telah memenuhi standar yang telah ditetapkan.

Penilaian kesesuaian dapat dilakukan oleh pihak pertama (produsen), pihak kedua (konsumen), atau pihak ketiga (pihak selain produsen dan konsumen), sejauh pihak tersebut memiliki kompetensi untuk memenuhi persyaratan yang ditetapkan oleh KAN.

Sertifikasi produk tanda SNI adalah kegiatan oleh pihak ketiga yang independen dalam memberikan jaminan tertulis yang menyatakan bahwa suatu produk (termasuk proses dan jasa) telah memenuhi persyaratan Standar Nasional Indonesia (SNI). Tanda ini dibubuhkan pada barang, kemasan barang dan/atau label. BSN menyatakan bahwa pembubuhan tanda SNI pada sebuah produk memberikan manfaat tak hanya bagi produsen saja tetapi juga bagi konsumen, pelaku usaha dan pemerintah yang antara lain sebagai berikut:

1. Memberi informasi kepada pihak-pihak yang berkepentingan dengan suatu produk bahwa produk tersebut telah memenuhi $\mathrm{SNI}$;

2. Untuk mengatasi kekhawatiran konsumen, pengguna dan semua pihak yang berkepentingan akan kualitas suatu produk;

3. Meningkatkan keberterimaan produk oleh konsumen;

4. Meningkatkan daya saing suatu produk karena kualitas produk tersebut lebih terjamin

Kegiatan penilaian kesesuaian

dilakukan melalui pengujian, inspeksi dan sertifikasi oleh LPK yang telah diakreditasi oleh KAN (UU No 20 tahun 2014). Sesuai dengan PP No. 102 tahun 2000, untuk keperluan menjamin kompetensi lembaga penilaian kesesuaian dilakukan melalui proses akreditasi. KAN sebagai Badan Akreditasi Nasional mempunyai tugas untuk memberikan akreditasi kepada LPK (Lembaga Inspeksi, Laboratorium Pengujian dan Lembaga Sertifikasi).
LPK yang telah diakreditasi oleh KAN mempunyai hak untuk menerbitkan sertifikat sesuai dengan lingkup akreditasinya, seperti Lembaga Sertifikasi berkaitan dengan sistem manajemen, produk, dan personel. Laboratorium pengujian mempunyai wewenang untuk melakukan pengujian terhadap sampel, metode dan peralatan. Lembaga Inspeksi akan melakukan inspeksi terhadap barang, jasa, proses, sistem, teknologi dan instalasi.

Mekanisme pelaksanaan akreditasi Lembaga Sertifikasi Produk (LSPro) mengacu kepada pemenuhan persyaratan standar ISO/IEC 17065 dan ISO/IEC 17067. Untuk pelaksanaan akreditasi Laboratorium Pengujian mengacu kepada pemenuhan persyaratan standar ISO/IEC 17025. Selanjutnya mekanisme akreditasi Lembaga Inspeksi (LI) mengacu kepada pemenuhan persyaratan standar ISO/IEC 17020.

Standar ISO/IEC 17065 digunakan sebagai dokumen persyaratan untuk menetapkan keberterimaan hasil audit berdasarkan persyaratan manajemen mutu lembaga sertifikasi produk dan ISO/IEC 17067 persyaratan kompetensi teknis pelaksanaan skema penilaian kesesuaian (ISO,2012). Struktur Organisasi Lembaga Sertifikasi Produk (LSPro) dapat dilihat dalam gambar 2.

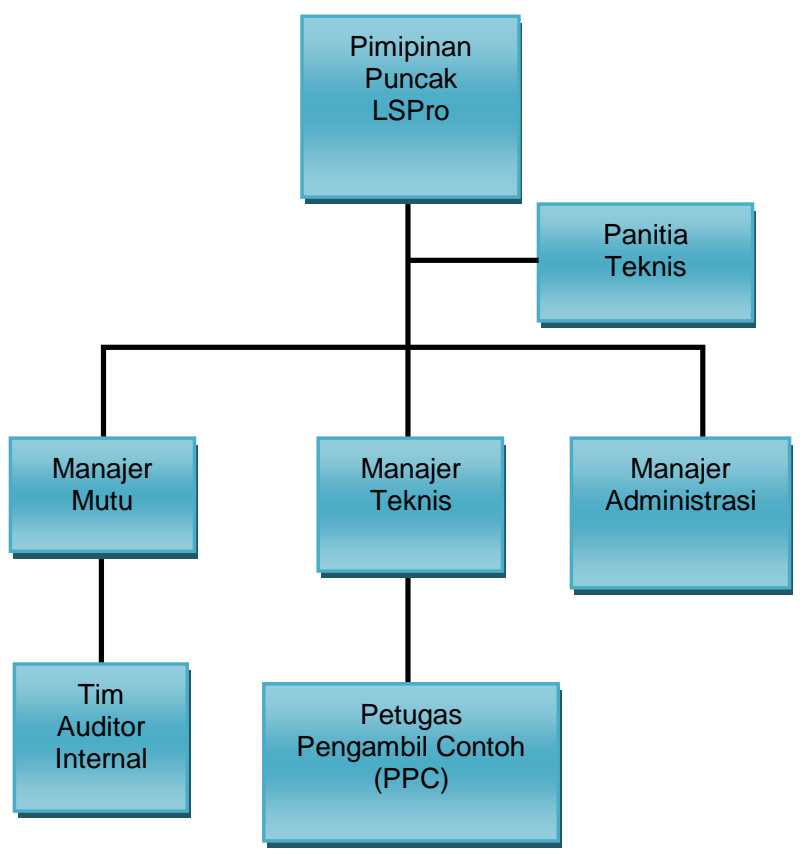

Gambar 2. Struktur Organisasi Lembaga Sertifikasi (LSPro)

\section{c. Standar ISO/IEC 17025}

Standar ISO/IEC 17025 digunakan sebagai dokumen persyaratan untuk 
menetapkan keberterimaan hasil pengujian berdasarkan persyaratan manajemen mutu laboratorium dan persyaratan kompetensi teknis(Firdaus H., 2015). Struktur Organisasi Laboratorium Pengujian dapat dilihat dalam gambar 3.

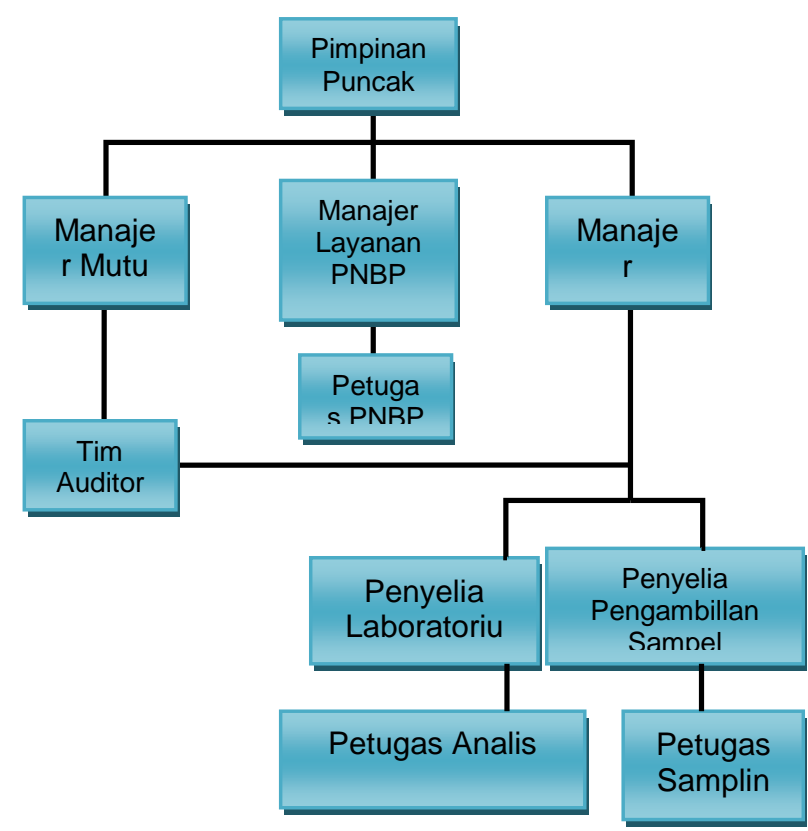

Gambar 3. Struktur Organisasi Laboratorium Pengujian

Standar ISO/IEC 17025:2017 merupakan standar tentang akreditasi laboratorium yang menjamin hasil pengukuran dan kalibrasi memiliki tingkat kepercayaan yang tinggi (Anastopoulus, 2017). Pada standar diatur beberapa persyaratan yaitu: (KAN, 2017)

1. Persyaratan umum yang terdiri dari manajemen ketidakberpihakan dan kerahasiaan.

2. Persyaratan struktural yang terdiri dari struktur organisasi dan manajemen puncak serta mekanisme untuk menjaga ketidakberpihakan.

3. Persyaratan sumberdaya yang terdiri dari pengelolaan personil, fasilitas serta ketelusuran metrologi.

4. Persyaratan proses yang terdiri dari kaji ulang permintaan, validasi metode uji, pengambilan sampel, kalibrasi, ketidakpastian pengukuran, rekaman teknis, ketidakpastian ukuran, pelaporan hasil serta penanganan keluhan.

Persyaratan manajemenyang terdiri dari dokumentasi sistem manajemen umum, pengendalian dokumen, pengendalian rekaman, tinjauan manajemen, audit internal, tindakan korektif serta tindakan pencegahan (Hadi, A.,2018).

\section{METODE PENELITIAN}

\section{a. Metode Pengumpulan Data}

Sebagaimana disampaikan pada tujuan dari penelitian ini, metode yang digunakan adalah analisis deskriptif kuantitatif, terhadap persepsi kesiapan laboratorium dan fasilitas litbang keantariksaan di satuan kerja LAPAN berdasarkan pemenuhan persyaratan akreditasi LPK. Pengumpulan data dilakukan melalui penyebaran kuesioner kepada 40 responden pengelola laboratorium dan fasilitas keantariksaan serta observasi lapangan ke laboratorium dan fasilitas keantariksaan di empat satuan kerja teknis LAPAN. Pada tahap ini dilakukan pengumpulan data dan informasi kelembagaan dan kesiapan pemenuhan persyaratan akreditasi LPK.

\section{b. Metode Validasi Data}

Pada penelitian ini dilakukan uji validitas dan uji reliabilitas terhadap hasil pengolahan data.

- Uji Validitas

Uji validitas dilakukan untuk mengetahui tingkat kecermatan yang kitajadikan alat ukur dapat menjalankan fungsi ukurnya.

Tabel 1 Output Corrected Item-Total Correlation Uji Validitas

\begin{tabular}{lll}
\hline & $\begin{array}{l}\text { Output } \\
\text { Corrected }\end{array}$ & R Tabel \\
Pertanyaan & Total Correlation & \\
\hline P1 & 0.654 & 0.3120 \\
P2 & 0.557 & 0.3120 \\
P3 & 0.632 & 0.3120 \\
P4 & 0.542 & 0.3120 \\
P5 & 0.442 & 0.3120 \\
P6 & 0.658 & 0.3120 \\
P7 & 0.596 & 0.3120 \\
P8 & 0.634 & 0.3120 \\
P9 & 0.661 & 0.3120 \\
P10 & 0.578 & 0.3120 \\
P11 & 0.347 & 0.3120 \\
P12 & 0.531 & 0.3120 \\
P13 & 0.589 & 0.3120 \\
P14 & 0.622 & 0.3120 \\
P15 & 0.354 & 0.3120
\end{tabular}




\begin{tabular}{lll}
\hline & $\begin{array}{l}\text { Output } \\
\text { Corrected Item- }\end{array}$ & R Tabel \\
Potal Correlation & \\
\hline P16 & 0.587 & 0.3120 \\
P17 & 0.476 & 0.3120 \\
P18 & 0.521 & 0.3120 \\
P19 & 0.623 & 0.3120 \\
P20 & 0.424 & 0.3120
\end{tabular}

Dari semua pertanyaan pada yang ditanyakan pada reponden, dapat dilihat bahwanilainya diatas dari nilai $R$ tabel yang artinya semua pertanyaan pada kuesioner inibisa digunakan valid pada penelitian ini.

\section{- Uji Reliabilitas}

Uji reliabilitas merupakan indeks yang menunjukkan sejauh mana suatualat pengukur dapat dipercaya. Uji reliabilitas dapat dikatakan reliabel jikamempunyai nilai koefisien alpha $>0,6$. Berikut tabel hasil uji reliabilitas

Tabel 2 Nilai Cronbach's Alpha Uji Reliabilitas

\begin{tabular}{rr}
\hline Cronbach's Alpha & N of ltem \\
\hline .868 & 20 \\
\hline
\end{tabular}

Hasil pengujian menunjukan bahwa nilai Cronbach's Alpha untuk setiap indikator diperoleh alpha > 0,6 sehingga kuesioner penelitian untuk masing-masing indikatordinyatakan reliabel dan telah memenuhi syarat reliabilitas sebagai instrumentpenelitian.

\section{c. Metode Analisis Data}

Pada penelitian ini menggunakan dua metode analisis yaitu analisis SWOT dan analisis kesenjangan

\section{- Metode Analisis SWOT}

Metode analisis SWOT digunakan untuk mengidentifikasi potensi pengembangan organisasi LAPAN menjadi LPK bidang penerbangan dan antriksa ditinjau dari aspek regulasi, kelembagaan, sarana dan prasarana, kompetensi sumber daya manusia serta persyaratan akreditasi lembaga inspeksi, laboratorium pengujian dan lembaga sertifikasi produk. Dalam analisis SWOT ini digunakan data primer yang diperoleh dari hasil survei lapangan dengan responden key person pengelola laboratorium Satker LAPAN.

Analisis SWOT adalah analisis kondisi internal maupun eksternal suatu organisasi yang selanjutnya akan digunakan sebagai dasar untuk merancang strategi kompetitif untuk pengembangan organisasi. Analisis internal meliputi peniaian terhadap faktor kekuatan(Strength) dankelemahan

(Weakness). Sementara, analisis eksternalmencakup faktor peluang (Opportunity) dan tantangan (Threath).

Perhitungan analisis SWOT yang dikembangkan oleh Pearce danRobinson(1998) bertujuan untuk mengetahui secara pasti posisi organisasi yang sesungguhnya. Perhitungan yang dilakukan melalui tiga tahap, yaitu:

1. Melakukan perhitungan skor (a) dan bobot (b) point faktor serta jumlah total perkalian skor dan bobot $(c=a \times$ b) pada setiap faktor S-W-O-T;Pilihan rentang besaran skor lazim digunakan adalah dari 1 sampai 10, dengan asumsi nilai 1 berarti skor yang paling rendah dan 10 berarti skor yang paling tinggi. Perhitungan bobot (b) masing-masing point faktor dilaksanakan secara saling ketergantungan. Artinya, penilaian terhadap satu point faktor adalah dengan membandingkan tingkat kepentingannya dengan point faktor lainnya.

2. Melakukan pengurangan antara jumlah total faktor $S$ dengan $W$ (d) dan faktor $O$ dengan $\mathrm{T}(\mathrm{e})$; Perolehan angka $(\mathrm{d}=\mathrm{x})$ selanjutnya menjadi nilai atau titik pada sumbu $\mathrm{X}$, sementara perolehan angka $(\mathrm{e}=$ y) selanjutnya menjadi nilai atau titik pada sumbu Y;

3. Mencari posisi organisasi yang ditunjukkan oleh titik $(\mathrm{x}, \mathrm{y})$ pada kuadran SWOT

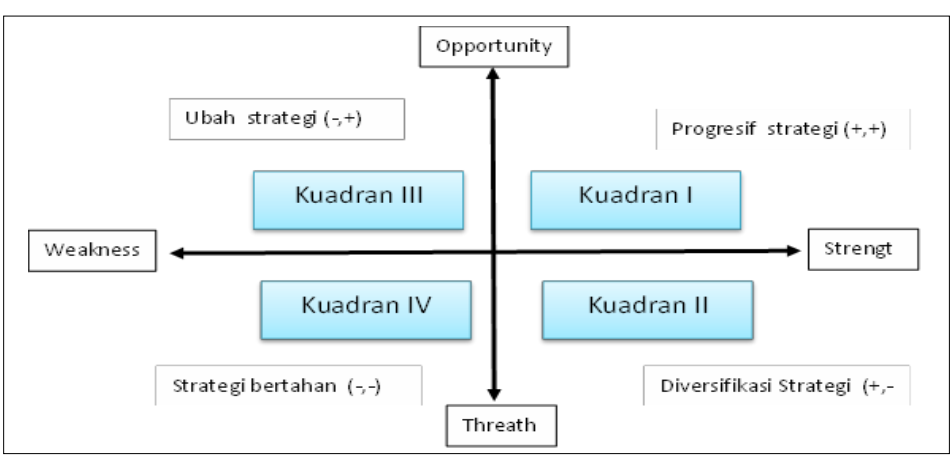

Gambar 4 Kuadran SWOT

- Posisi Kompetitif Organisasi

a. Kuadran I (positif, positif)

Posisi ini menandakan sebuah organisasi yang kuat dan berpeluang. Rekomendasi strategi yang diberikan adalah progresif, artinya organisasi dalam kondisi prima dan mantap sehingga sangat dimungkinkan 
untuk terus melakukan ekspansi, memperbesar pertumbuhan dan meraih kemajuan secara maksimal.

b. Kuadran II (positif, negatif)

Posisi ini menandakan sebuah organisasi yang kuat namun menghadapi tantangan yang besar. Rekomendasi strategi yang diberikan adalah diversifikasi strategi, artinya organisasi dalam kondisi mantap namun menghadapi sejumlah tantangan beratsehingga diperkirakan roda organisasi akan mengalami kesulitan untuk terus berputar bila hanya bertumpu pada strategi sebelumnya. Oleh sebab itu, organisasi disarankan untuk segera memperbanyak ragam strategi taktisnya.

c. Kuadran III (negatif, positif)

Posisi ini menandakan sebuah organisasi yang lemah namun sangat berpeluang. Rekomendasi strategi yang diberikan adalah ubah strategi, artinya organisasi disarankan untuk mengubah strategi sebelumnya. Sebab, strategi yang lama dikhawatirkan sulit untuk dapat menangkap peluang yang ada sekaligus memperbaiki kinerja organisasi.

d. Kuadran IV (negatif, negatif)

Posisi ini menandakan sebuah organisasi yang lemah dan menghadapi tantangan besar. ekomendasi strategi yang diberikan adalah strategi bertahan, artinya kondisi internal organisasi berada pada

pilihan dilematis. Oleh karenanya

organisasi disarankan untuk menggunakan strategi bertahan, mengendalikan kinerja internal agar tidak semakin terperosok. Strategi ini dipertahankan sambil terus berupaya membenahi diri.

\section{- Metode Analisis Kesenjangan}

Analisis kesenjangan (Gap analysis) menerupakan metode dengan membandingkan kondisi yang ada dengan kondisi yang akan dicapai. Dengan analisis kesenjangan dapat mengidentifikasi kebutuhan yang bisa mengurangi kesenjangan yang ada. Untuk melaksanakan analisis kesenjangan diperlukan tujuanjelas yang ingin diperoleh. Dalam pengambilan data pastikan bahwa informasi yang dikumpulkan berasal dari sumber yang tepat dan analisis kondisi yang ada. Langkah terakhir adalah mengidentifikasi bagaimana kita dapat menjembatani kesenjangan yang terjadi diantara kondisi saat ini dan target kita dimasa yang akandatang.Selain itu analisis kesenjangan ini dapat juga melihat kesiapan dari sebuah sistem yang ditetapkan dan dilaksanakan.

$\mathrm{Di}$ dalam proses penerapan ISO dan atau SNI, analisis kesenjangan merupakan langkah awal.(Admaja, A. F. S. , 2013) Dengan adanya analisis kesenjangan diharapkan dapat diketahui langkah-langkah apa yang perlu diambil agar dengan mudah dapat mencapai kondisi atau standar yang diharapkan, dalam hal ini sesuai dengan standard yang ditentukan di dalam ISO dan atau SNI yang dijadikan acuan.

Analisis kesenjangan dilakukan dengan menilai kesiapan dengan menggunakan indeks kesiapan. Indeks kesiapan diperoleh dari penilaian terhadap kondisi yang ada saat ini, dengan penilaian mengacu pada klausul ISO/IEC 17025 (ISO,2017). Tingkat kesiapan dinilai dengan menggunakan skala Likert $(0,1,2,3,4)$ yang mewakili : Tidak Memadai Kurang Memadai - Cukup Memadai Memadai - Sangat Memadai.

Tabel 3. Skala Likert tingkat kesiapan

\begin{tabular}{|c|c|c|}
\hline Nilai & Status & Keterangan \\
\hline 0 & $\begin{array}{l}\text { Tidak } \\
\text { memadai }\end{array}$ & $\begin{array}{l}\text { Jika persyaratan belum } \\
\text { dilakukan sama sekali }\end{array}$ \\
\hline 1 & $\begin{array}{l}\text { Kurang } \\
\text { memadai }\end{array}$ & $\begin{array}{l}\text { Jika persyaratan mulai } \\
\text { dilakukan }\end{array}$ \\
\hline 2 & $\begin{array}{l}\text { Cukup } \\
\text { memadai }\end{array}$ & $\begin{array}{l}\text { Persyaratan mulai } \\
\text { dilakukan dan } \\
\text { diterapkan }\end{array}$ \\
\hline 3 & Memadai & $\begin{array}{l}\text { Persyaratan sudah } \\
\text { dilakukan dan } \\
\text { diterapkan }\end{array}$ \\
\hline 4 & $\begin{array}{l}\text { Sangat } \\
\text { memadai }\end{array}$ & $\begin{array}{l}\text { Persyaratan sudah } \\
\text { dilakukan dan } \\
\text { diterapkan dan terdapat } \\
\text { dokumnetasi resmi }\end{array}$ \\
\hline
\end{tabular}

Nilai skala Likert tiap syarat dijumlah dan dibagi dengan nilaimaksimal . Hasil perhitungan inilah yang menjadi indeks kesenjangan(De Coi et al. (n.d).

Pada analisis ini akan dibagi beberapa kategori sesuai dengan klausul pada ISO 17025:

1. Klausul 4 Persyaratan Umum;

2. Klausul 5 Persyaratan Struktur;

3. Klausul 6 Persyaratan Sumber Daya;

4. Klausul 7 Persyaratan Proses;

5. Klausul 8 Persyaratan Sistem Manajemen 


\section{HASIL DAN PEMBAHASAN}

\section{a. Analisis SWOT (Strength Weakness Opportunities Threats)}

Analisis SWOT adalah identifikasi berbagai faktor secara sistematis untuk merumuskan strategi pengembangan organisasi (Rangkuti, 2004). Analisis ini didasarkan pada logika yang dapat memaksimalkan kekuatan (strenght) dan peluang (opportunities) namun secara bersamaan meminimalkan kelemahan (weakness) dan ancaman (threats). Analisis SWOT menempatkan posisi masa depan dengan modal dasar kekuatan dan kelemahan yang kemudian digunakan untuk memperkirakan apa saja peluangataupun ancaman.

Analisis SWOT memerlukan variabel, rating, skor dan bobot dari faktor internal dan faktor eksternal. Faktor internal merupakan lingkungan internal yang terdiri dari kekuatan (Strenght) dan kelemahan (Weakness) dengan melihat kondisi dan kemampuan yang dimiliki organisasi. Berikut ini merupakan faktor internal yang diidentifikasi untuk mengukur kesiapan LAPAN menjadi LPK:

Tabel 4. Skor Faktor Internal

\begin{tabular}{llll}
\hline $\begin{array}{l}\text { VariabelStren } \\
\text { gth }\end{array}$ & Bobot & Rating & Skor \\
\hline $\begin{array}{l}\text { Kompetensip } \\
\text { ersonel }\end{array}$ & 0,116 & 3,88 & 0,45 \\
\hline $\begin{array}{l}\text { Jumlahperson } \\
\text { el }\end{array}$ & 0,096 & 2,7 & 0,26 \\
\hline $\begin{array}{l}\text { PemahamanS } \\
\text { NI }\end{array}$ & 0,097 & 3,51 & 0,34 \\
\hline $\begin{array}{l}\text { Fasilitaspeng } \\
\text { ujian }\end{array}$ & 0,098 & 3,65 & 0,36 \\
\hline $\begin{array}{l}\text { Lingkup } \\
\text { sertifikasiprod } \\
\text { uk }\end{array}$ & 0,097 & 3,3 & 0,32 \\
\hline Total & & & $\mathbf{1 , 7 3}$ \\
\hline $\begin{array}{l}\text { VariabelWeak } \\
\text { ness }\end{array}$ & Bobot & Rating & Skor \\
\hline $\begin{array}{l}\text { Keterbatasan } \\
\text { tenaga ahli }\end{array}$ & 0,114 & $-2,13$ & $-0,24$ \\
\hline $\begin{array}{l}\text { Pengalaman } \\
\text { sedikit }\end{array}$ & 0,095 & $-2,21$ & $-0,21$ \\
\hline $\begin{array}{l}\text { Produk } \\
\text { terbatas }\end{array}$ & 0,094 & $-3,13$ & $-0,29$ \\
\hline $\begin{array}{l}\text { Persyaratan } \\
\text { Akreditasi } \\
\text { LPK }\end{array}$ & 0,096 & $-3,65$ & $-0,35$ \\
\hline Layanan & 0,097 & $-2,1$ & $-0,20$ \\
\hline & & \\
\hline
\end{tabular}

konsumen

Total $-1,30$

Faktor ekternal merupakan lingkungan ekternal terdiri dari peluang (Opportunities) dan ancaman (Threath). Faktor ekternal terdiri dari analisis lingkungan makro dan mikro bertujuan mengidentifikasi peluang dan ancaman makro yang berdampak terhadap pelaksanaan standardisasi yang dilakukan organisasi. Berikut ini merupakan faktor eksternal yang diidentifikasi untuk mengukur kesiapan LAPAN menjadi LPK:

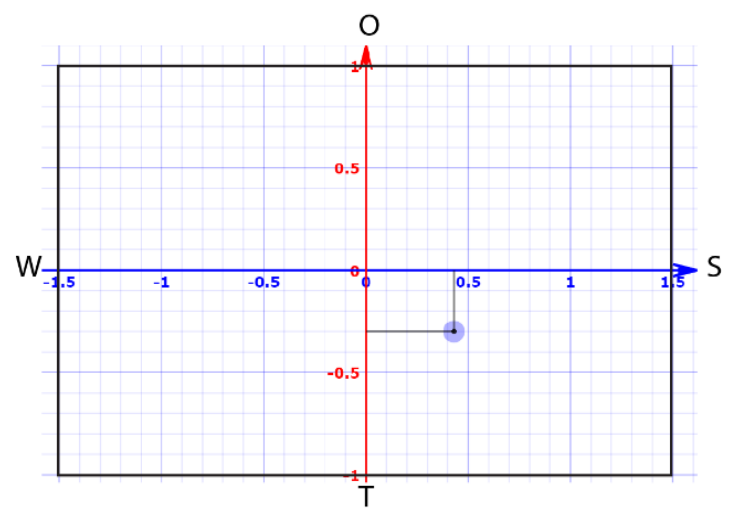

Tabel 5. Skor Faktor Eksternal

\begin{tabular}{|c|c|c|c|}
\hline $\begin{array}{l}\text { VariabelOpport } \\
\text { unities }\end{array}$ & Bobot & Rating & Skor \\
\hline $\begin{array}{l}\text { Lingkup } \\
\text { akreditasi yang } \\
\text { belum tersentuh }\end{array}$ & 0,117 & 2,01 & 0,24 \\
\hline $\begin{array}{l}\text { Penerapan SNI } \\
\text { wajib }\end{array}$ & 0,103 & 2,5 & 0,26 \\
\hline $\begin{array}{l}\text { Kemajuan } \\
\text { teknologi }\end{array}$ & 0,088 & 3,3 & 0,29 \\
\hline $\begin{array}{l}\text { Dukungan } \\
\text { kebijakan } \\
\text { pemerintah }\end{array}$ & 0,094 & 2,7 & 0,25 \\
\hline $\begin{array}{l}\text { Pengembangan } \\
\text { sertifikasi }\end{array}$ & 0,104 & 2,1 & 0,22 \\
\hline Total & & & 1,26 \\
\hline $\begin{array}{l}\text { VariabelThreat } \\
h\end{array}$ & Bobot & Rating & Skor \\
\hline $\begin{array}{l}\text { Keterbatasan } \\
\text { tenaga ahli }\end{array}$ & 0,1 & $-3,19$ & $-0,32$ \\
\hline $\begin{array}{l}\text { Pengalaman } \\
\text { sedikit }\end{array}$ & 0,096 & $-3,76$ & $-0,36$ \\
\hline Produk terbatas & 0,121 & $-2,11$ & $-0,26$ \\
\hline $\begin{array}{l}\text { Persyaratan } \\
\text { Akreditasi LPK }\end{array}$ & 0,091 & $-3,699$ & $-0,34$ \\
\hline $\begin{array}{l}\text { Layanan } \\
\text { konsumen }\end{array}$ & 0,086 & $-3,25$ & $-0,28$ \\
\hline Total & 1 & & $-1,55$ \\
\hline
\end{tabular}


Penerapan strategi pengembangan, yaitu dengan membuat matriks SWOT. Berdasarkan matriks SWOT dapat disusun empat strategi utama yaitu SO (Strenghts and Opportunities), WO (Weakness and Opportunities), ST (Strenghts and Threats), dan WT (Weakness and Threats).

Penegasan terhadap tingkat keseimbangan antara kekuatan (Strenght) dan kelemahan (Weakness) pada sumbu $\mathrm{X}$ (positif) serta peluang (Opportunities) dan ancaman (Threats) pada sumbu $Y$ (negatif) dalam matriks analisis SWOT diperlukan dalam penentuan strategi. Perhitungan total skor didapat dari perhitungan Internal Faktor Analisis dan External Faktor Analisis sehingga perhitungan total skor untuk variabel kekuatan menjadi 1,727 dan total skor untuk variabel kelemahan 1,301 sedangkan untuk variable peluang menjadi 1,255 dan total skor untuk variabel ancaman menjadi 1,551 sehingga diperoleh koordinat:

Sumbu $Y=$ peluang - ancaman $=1,255-$ $1,551=-0,296$.

Sumbu $X=$ kekuatan - kelemahan $=1,727-$ $1,301=0,42$

Gambar 5 Posisi Strategi Pengembangan LPK pada Kuadran 2 (positif,negatif)

Gambar diatas dapat dilihat bahwa posisi organisasi LAPAN terletak pada kuadran 2 yang berarti Organisasi LAPAN mendukung kegiatan diversifikasi strategi (ST) sehingga dapat menggunakan kekuatan internalnya guna mengambil keuntungan dari ancaman eksternal. Posisi diversifikasi strategi ini menandakan organisasi LAPAN dalam kondisi mantap namun menghadapi sejumlah tantangan berat sehingga diperkirakan operasional organisasi akan mengalami kesulitan untuk melaksanakan kegiatan standardisasi bila hanya bertumpu pada struktur organisasi yang ada. Oleh karenanya, organisasi disarankan untuk segera memperbanyak ragam strategi pengembangan struktur organisasi/ kelembagaan penerapan standar.

Salah satu strategi pengembangan kelembagaan penerpan standar kekuatan kompetensi personel dan kelengkapan fasilitas dan sarana pengujian yang dimiliki oleh satuan kerja teknis LAPAN (Pustekbang, PSTA, Pusteksat, Pustekroket) untuk didorong menjadi laboratorium pengujian melalui pendampingan penyiapan pemenuhan persyaratan standar ISO/IEC 17025 khususnya terkait legalitas struktur laboratorium.Skema pengembangan struktur satuan kerja teknis menjadi laboratorium pengujian
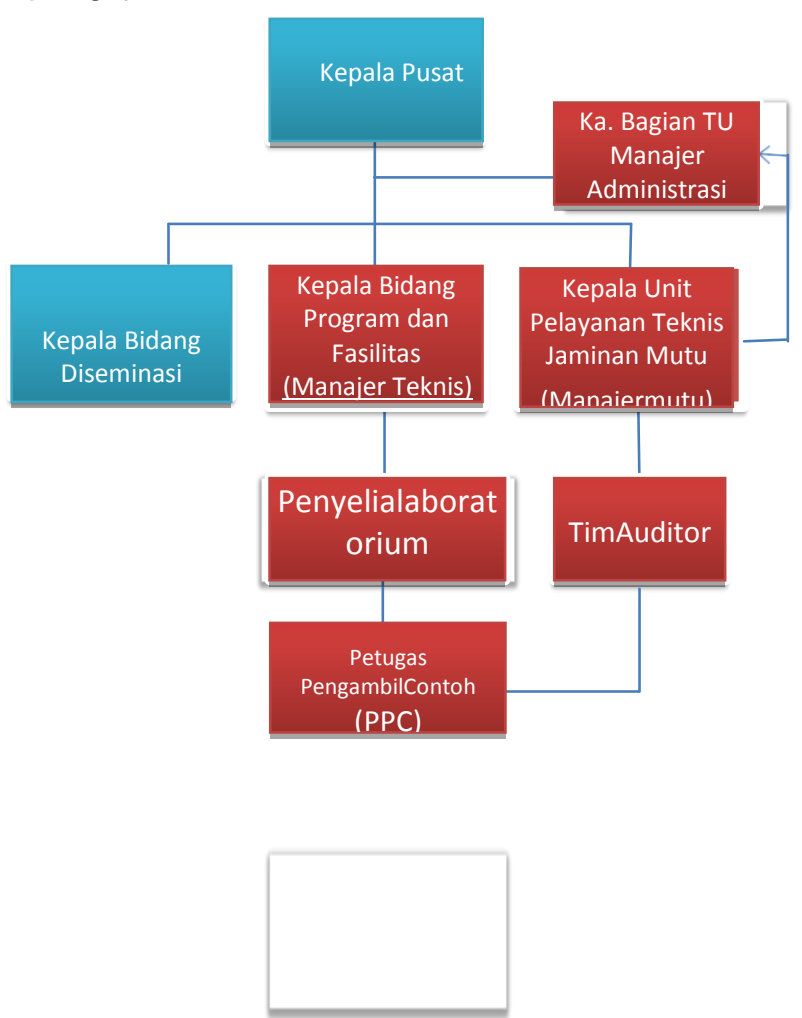

Gambar 6 Skema Pengembangan

Oraganisasi Laboratorium Pengujian

Sedangkan untuk pemanfaatan peluang dukungan kebijakan regulasi dan pemberlakuan penerapan SNI wajib, Pusispan selaku satuan kerja yang berfungsi melaksanakan sertifikasi didorong untuk menjadi Lembaga Sertifikasi Produk (LSPro) melalui pendampingan penyiapan pemenuhan persyaratan standar ISO/IEC 17065 dan ISO/IEC 17067. 


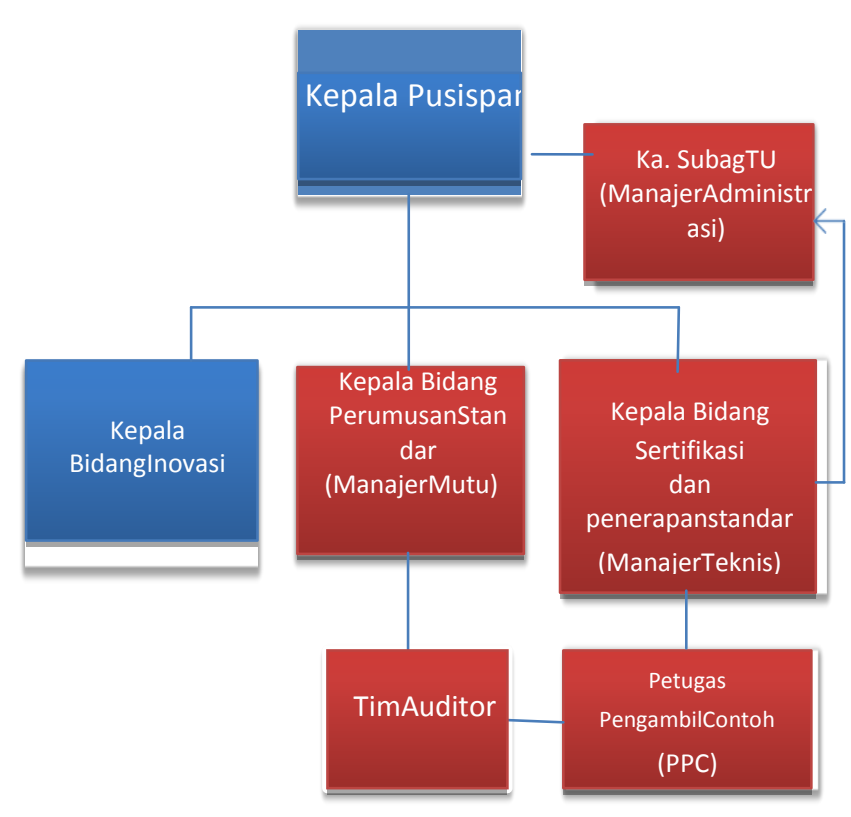

Gambar 7 Skema Pengembangan Organisasi Lembaga Sertifikasi Produk (LSPro)

Berdasarkan kedudukan dan keberadaan laboratorium dan fasilitas litbang keantariksaan berada dibeberapa satuan kerja teknis secara tersebar dan terpisah dari Pusispan selaku satuan kerja yang bertugas dalam kegiatan standardisasi maka dibuat skema penilaian kesesuaian yang mandiri dan terintegrasi dimana Pusispan akan menjadi LSPro untuk pelayanan sertifikasi produk namun mensubkontrakan atau alih dayakan kegiatan pengujian dan inspeksi kepada laboratorium pengujian dan lembaga inspeksi yang ada di satuan kerja teknis. Dalam hal pihak ketiga membutuhkan pengujian ataupun inspeksi terhadap barang/jasa yang dihasilkan maka laboratorium pengujian dan lembaga inspeksi dapat melakukan pelayanan secara langsung.

\section{b. Analisis Kesenjangan Laboratorium Sesuai dengan ISO/IEC 17025}

Analisis dan pembahasan merupakan hasil pengukuran/assessment langsung di lapangan untuk melihat tingkat kesiapan laboratorium di satuan kerja sebagai laboratorium pengujian. Pengukuran dinilai dari pemenuhan persyaratan ISO/IEC 17025:2017 yang terdiri dari aspek legal, struktur organisai, sumberdaya, proses dan sistem manajemen yang terdapat pada klausul (Brocks, H. et al., 2010).
- Aspek Legal dan Struktur Organisasi

Tabel 6 Kesenjangan Persyaratan

Laboratorium Sesuai dengan ISO/IEC 17025

Nama Laboratorium Klausul 4 Klausul 5

Laboratorium

Aerostruktur -

$0,8 \quad 0,06$

Pustekbang Rumpin

Laboratorium Uji

Aerodinamika -

$0,8 \quad 0,1$

Pustekbang Rumpin

Laboratorium Uji

Propulsi Pustekbang

0,8

0,12

Rumpin

Laboratorium

Pusteksat

1

0,77

Rancabungur

Laboratorium

Elektronika Radar

0,15

0,6

Hujan

Laboratorium Pustek

Roket

Secara umum, laboratorium pada satuan kerja yang dikunjungi memiliki kesenjangan persyaratan yang tinggi untuk aspek umum, klausul 4 ISO/IEC 17025: 2017. Klausul ini menyangkut ketidakberpihakan dan kerahasiaan. Kesenjangan yang tinggi terjadi ini karena laboratorium belum memiliki kebijakan mengenai ketidakberpihakan dan kerahasiaan.

Klausul 5 Persyaratan Struktural ISO/IEC17025: 2017, laboratorium yang bernaung di bawah Pustekbang memiliki skor yang rendah. Hal ini karena salah satu laboratorium, yakni Laboratorium Uji Material dalam proses pengajuan akreditasi KAN ISO/IEC 17025. Legalitas hukum, manajemen laboratorium, ruang lingkup kegiatan laboratorium, struktur organisasi laboratorium telah dibentuk dan di nilai oleh penilai KAN dan tidak ada temuan terkait klausul ini. Sistem yang sudah dibangun bisa diterapkan juga pada laboratorium lain. Beberapa prosedur yang diwajibkan dalam ISO/IEC 17025 pada dasarnya sudah dibuat untuk mendukung Laboratorium Uji Material namun belum disesuaikan untuk mencakup laboratorium uji lainnya.

Secara struktur, laboratorium tidak berada di bawah bidang program dan fasilitas maupun bidang diseminasi tapi langsung di bawah pengelolaan Pustekbang LAPAN. Sebagai pimpinan tertinggi laboratorium adalah Kepala Pustekbang LAPAN. Penanggungjawab mutu dan teknis dijabat oleh tenaga fungsional perekayasa/peneliti. 
Kepala Pustekbang menerbitkan Surat Keputusan pembentukan organisasi Laboratorium Uji Material untuk keperluan akreditasi KAN. Untuk jangka menengah, apabila Laboratorium Uji Material sudah mendapatkan akreditasi, laboratorium dapat mengajukan perluasan ruang lingkup yang mencakup laboratorium uji lainnya nama laboratorium disesuaikan menjadi "Laboratorium Uji Pustek Penerbang".

Sedangkan untuk Laboratorium Uji Elektronika Radar Hujan yang berada di bawah Pusat Sains dan Teknologi Atmosfer, meskipun sudah ada laboratorium yang terakreditasi di sana, namun penunjukan Kepala Bidang Fasilitas sebagai "Manajemen Puncak" laboratorium uji oleh Kepala PSTA tidak sesuai dengan persyaratan ISO/IEC 17025. Akibatnya skor untuk Klausul 5 Persyaratan Struktural cukup tinggi (0.6). Untuk Klausul 4 Persyaratan Umum, skor yang diperoleh rendah $(0.15)$ karena mengikuti implementasi kebijakan mengenai ketidakberpihakan dan kerahasiaan yang diterapkan oleh Laboratorium Uji Kimia PSTA. Atau bisa dikatakan ini yang telah memilik tingkat kesiapan yang tinggi sebesar $85 \%$. Secara struktur, laboratorium tidak berada di bawah Bidang Program dan Fasilitas maupun Bidang Diseminasi tapi langsung di bawah pengelolaan PSTA LAPAN. Lab Elektronika adalah fungsi pendukung pemeliharaan instrumen ukur di PSTA LAPAN dan belum difungsikan sebagai laboratorium uji. Beberapa prosedur yang diwajibkan dalam ISO/IEC 17025 pada dasarnya sudah dibuat untuk mendukung Lab Uji Kimia namun belum disesuaikan untuk mencakup Lab Uji lainnya. Lab Uji Elektronika direncanakan untuk dapat melakukan pengujian radar hujan dimana saat ini belum semua instrumen yang diperlukan untuk menguji seluruh parameter SNI (Sekarang masih RSNI Radar Hujan Persyaratan Kinerja Sistem dan Operasi) dapat dipenuhi. Laboratorium Pusteksat juga memiliki skor kesenjangan yang tinggi untuk klausul 5 yakni 0.77 . Secara struktur organisasi, Pusteksat sudah menetapkan fungsi pengelolaan fasilitas dimana laboratorium termasuk di dalamnya. Laboratorium juga masuk dalam organisasi kerekayasaan. Namun sistem manajemen ISO/IEC 17025 belum ditetapkan.Secara fasilitas pengujian Pusteksat memiliki instrument yang lengkap khusus untuk pengujian satelit. Lab uji Pusteksat dapat melakukan pengujian seluruh parameter SNI satelit kubus yang akan ditetapkan.
Laboratorium Pustek Roket memiliki skor kesenjangan yang tinggi untuk klausul 5 yakni 0.75 . Hal ini disebabkan Laboratorium saat ini ditempatkan sebagai unit penunjang di bawah struktur kerekayasaan yang berbasis proyek/ program. Laboratorium belum memiliki surat keputusan penetapan fungsi laboratorium.

- Aspek Sumber Daya, Proses dan Sistem Manajemen

Tabel7. Kesenjangan Persyaratan Laboratorium sesuai dengan ISO/IEC 17025

\begin{tabular}{|c|c|c|c|}
\hline Nama Laboratorium & $\begin{array}{l}\text { Klau } \\
\text { sul } 6\end{array}$ & $\begin{array}{l}\text { Klau } \\
\text { sul } 7\end{array}$ & $\begin{array}{l}\text { Klau } \\
\text { sul } 8\end{array}$ \\
\hline $\begin{array}{l}\text { Laboratorium } \\
\text { Aerostruktur - } \\
\text { Pustekbang Rumpin }\end{array}$ & 0,42 & 0,66 & 0,5 \\
\hline $\begin{array}{l}\text { Laboratorium Uji } \\
\text { Aerodinamika - } \\
\text { Pustekbang Rumpin }\end{array}$ & 0,53 & 0,66 & 0,5 \\
\hline $\begin{array}{l}\text { Laboratorium Uji } \\
\text { Propulsi Pustekbang } \\
\text { Rumpin }\end{array}$ & 0,66 & 0,77 & 0,5 \\
\hline $\begin{array}{l}\text { Laboratorium } \\
\text { Pusteksat } \\
\text { Rancabungur }\end{array}$ & 0,87 & 0,9 & 0,86 \\
\hline $\begin{array}{l}\text { Laboratorium } \\
\text { Elektronika Radar } \\
\text { Hujan }\end{array}$ & 0,8 & 0,8 & 0,1 \\
\hline $\begin{array}{l}\text { Laboratorium Pustek } \\
\text { Roket }\end{array}$ & 0,95 & 0,9 & 1 \\
\hline
\end{tabular}

Secara umum dapat dilihat bahwa laboratorium yang berada di bawah Pustekbang memiliki kesiapan yang relatif tinggi untuk Klausul 6 Persyaratan Sumber Daya, Klausul 7 Persyaratan Proses, dan Klausul 8 Persyaratan Sistem Manajemen. Ini dilihat dari nilai kesenjangan yang rendah. Hal ini karena secara sistem dan dokumentasi laboratorium - laboratorium tersebut bisa menggunakan sistem dan dokumentasi Laboratorium Uji Material yang sedang dalam proses pengajuan akreditasi. Namun demikian laboratorium masih harus menyusun dokumentasi spesifik ruang lingkup ujinya masing - masing.

Hasil analisis kesenjangan ini juga didapatkan bahwa unit laboratorium yang mendapatan tingkat kesenjangan persyaratan yang rendah adalah laboratorium di Pustekbang. Hal ini dapat diartikan bahwa kesiapan akreditasi sesuai dengan ISO/IEC 17025untuk memenuhi sebagai laboratorium pengujian tinggi. 


\section{KESIMPULAN}

Dari hasil analisis SWOT didapatkan hasil yaitu posisi organisasi LAPAN dalam berada di kuadran II (positif, negatif). Posisi ini menandakan sebuah organisasi yang kuat namun menghadapi tantangan yang besar. Sehingga diperkirakan operasional organisasi akan mengalami kesulitan untuk menjalankan fungsi infrastruktur penerapan standar bila hanya bertumpu pada struktur organisasi yang ada. Untuk strategi agar penerapan standar maka di masa yang akan depan maka satuan kerja teknis LAPAN (Pustekbang, PSTA, Pusteksat, Pustekroket) untuk didorong menjadi laboratorium pengujian melalui pendampingan penyiapan pemenuhan persyaratan standar ISO/IEC 17025 khususnya terkait legalitas struktur laboratorium. Sedangkan untuk pelayanan sertifikasi produk (LSPro) dilakukan oleh Pusispan selaku satuan kerja yang bertugas dalam kegiatan standardisasi.Namun,untuk kegiatan pengujian dan inspeksi mensubkontrakan atau alih dayakan kepada laboratorium pengujian dan lembaga inspeksi yang ada di satuan kerja teknis. Dalam hal pihak ketiga membutuhkan pengujian ataupun inspeksi terhadap barang/jasa yang dihasilkan maka laboratorium pengujian dan lembaga inspeksi dapat melakukan pelayanan secara langsung (Zapata et al ,2007).

Untuk tingkat kesiapan laboratorium di satuan kerja teknis sebagai laboratorium pengujian dari hasil analisis kesenjangan didapat bahwa tingkat kesiapannya masih rendah. Unit laboratorium yang tingkat kesiapan sebagai laboratorium tinggi adalah unit laboratorium di Pusat Teknologi Penerbangan. Untuk unit yang lain perlu adanya perbaikan di aspek manajemen, struktur organisasi, prosedur dan dokumentasi.

\section{UCAPAN TERIMAKASIH}

Penulis mengucapkan terima kasih kepada manajemen puncak LAPAN, Pusispan LAPAN dan pihak-pihak yang telah mendukung penelitian ini.

\section{DAFTAR PUSTAKA}

Admaja, A. F. S. (2013). Studi Kesiapan Direktorat Standardisasi Dalam Menerapkan SNI ISO/IEC 17065. Buletin Pos dan Telekomunikasi, 11(3), 223-234.
Badan Standardisasi Nasional, (2018), Peraturan BSN Nomor 3 Tahun 2018 tentang Pedoman Pengembangan Standar Nasional Indonesia.

Brocks, H., Hemmmje, M. et al. (2010), The PARSE. Insight GAP Analysis. Fern Universitat in Hagen.

De Coi, J. L., Herder, E., Koeseling, .A et al. (n.d). A Model For Competence GAP Analysis. Germany: L3S Reserch Center and University of Hanonover.

Firdaus H. (2015). Sistem Manajemen Mutu Laboratorium ISO 17025: Solusi Peningkatan Kinerja Laboratorium Pengujian dan Kalibrasi di Pemerintah Daerah. http://www.smtp.lipi.go.id/. 10 Juli 2017

Freddy Rangkuti, 2004, Analisis SWOT Teknik Membedah Kasus Bisnis, PT. Gramedia, Jakarta

Hadi, A. (2018). Persyaratan Umum Kompetensi Laboratorium Pengujian \& Laboratorium Kalibrasi ISO/IEC 1025: 2017. Jakarta: PT Gramedia.

Herjanto, E., \&Rahmi, D. (2010). Kajian Kesiapan Pemberlakuan Secara Wajib Standar Mainan Anak-anak Study of Readines of the Compulsory Implementation of Toys Standards. Journal of Industrial Research (Jurnal Riset Industri), 4(1).

International Standard Organization, (2017), General Requirements for The Competence of Testing and Calibaration Laboratories.

International Standard Organization, (2012), Conformity assessment Requirements for bodies certifying products, processes and services.

Lembaga Penerbangan dan Antariksa Nasional, 2017, Peraturan Kepala Lembaga Penerbangan dan Antariksa Nasional Nomor 10 Tahun 2017 Yang Mengatur Tentang Pelaksanaan Standardisasi Penerbangan dan Antariksa, LAPAN, Jakarta.

Mansuette, B., \& Cebekhulu, B. (2017). Quality Control in a University Laboratory: Evaluating the Gap between ISO / IEC-17025 Requirements and the Thin Section Laboratory 's Processes ., 614-625.

Pemerintah Indonesia, (2000), Peraturan Pemerintah Nomor 102 Tahun 2000 Tentang Standardisasi Nasional. Sekretariat Negara.Jakarta. 
Pemerintah Indonesia, (2013), UndangUndang Nomor 21 Tahun 2013 Yang Mengatur Tentang Keantariksaan. Lembaran Negara RI Tahun 2013 Nomor $133 . \quad$ Sekretariat Negara.Jakarta.

Pemerintah Indonesia, (2014), UndangUndang Nomor 20 Tahun 2014 Yang Mengatur Tentang Standardisasi dan Penilaian Kesesuaian. Lembaran Negara RI Tahun 2014 Nomor 216. Sekretariat Negara.Jakarta.

Pemerintah Indonesia, (2018), Peraturan Pemerintah Nomor 38 Tahun 2018 Yang Mengatur Tentang Sistem Standardisasi dan Penilaian Kesesuaian Nasional. Lembaran Negara RI Tahun 2018 Nomor 110. Sekretariat Negara.Jakarta.

Pemerintah Indonesia, (2017), Peraturan Lembaga Penerbangan dan Antariksa Nasional Nomor 8 Tahun 2017 Yang Mengatur Tentang Perubahan atas
Peraturan Kepala Lembaga Penerbangan dan Antariksa Nasional Nomor 8 Tahun 2015 tentang Organisasi dan Tata Kerja Lembaga Penerbangan dan Antariksa Nasional, Berita Negara RI Tahun 2017 Nomor 1723, Sekretariat Negara. Jakarta.

Setiadi, B. (2011). Standar Nasional Indonesia (SNI) dan Young Professional. Disampaikan pada Workshop The Role of Young Professional in Standardization Tanggal 08 November 2011. Jakarta.

Shepherd, C. C. (2014). A Systems Engineering Approach to Quality Assurance for Aerospace Testing.

Zapata-Garcia, D., Llauradó, M., \& Rauret, G. (2007). Experience of implementing ISO 17025 for the accreditation of a university testing laboratory. Accreditation and quality assurance, 12(6), 317-322. 
